\title{
Vaccine preferences driving vaccine- decision making of different target groups: a systematic review of choice-based experiments
}

Marilyn Emma Diks ${ }^{1}$, Mickael Hiligsmann ${ }^{2}$ and Ingeborg Maria van der Putten ${ }^{2^{*}}$

\begin{abstract}
Background: Choice-based experiments have been increasingly used to elicit preferences for vaccines and vaccination programs. This study aims to systematically identify and examine choice-based experiments assessing (differences in) vaccine preferences of vaccinees, representatives and health advisors.

Methods: Five electronic databases were searched on choice-based conjoint analysis studies or discrete choice experiments capturing vaccine preferences of children, adolescents, parents, adults and healthcare professionals for attributes of vaccines or vaccine settings up to September 2020. Data was extracted using a standardized form covering all important aspects of choice experiments. A quality assessment was used to assess the validity of studies. Attributes were categorized into outcome, process, cost and other. The importance of attributes was assessed by the frequency of reporting and statistical significance. Results were compared between high-quality studies and lower-quality studies.

Results: A total of 42 studies were included, with the majority conducted in high-income countries after 2010 (resp. $n=34$ and $n=37$ ). Preferences of representatives were studied in nearly half of the studies $(47.6 \%)$, followed by vaccinees (35.7\%) and health advisors (9.5\%). Sixteen high-quality studies passed the quality assessment. Outcome- and cost- related attributes such as vaccine effectiveness, vaccine risk, cost and protection duration were most often statistically significant across both target groups, with vaccine effectiveness being the most important. Risks associated with vaccination, such as side effects, were more often statistically significant in studies targeting vaccinees, while cost-related attributes were more often statistically significant in studies of representatives. Processrelated attributes such as vaccine accessibility and time were least important across both target groups.
\end{abstract}

\footnotetext{
* Correspondence: i.vanderputten@maastrichtuniversity.nl

${ }^{2}$ Department of Health Services Research, Care and Public Health Research Institute (CAPHRI), Maastricht University, Duboisdomein 30, 6229 Maastricht, Netherlands

Full list of author information is available at the end of the article
}

(C) The Author(s). 2021 Open Access This article is licensed under a Creative Commons Attribution 4.0 International License, which permits use, sharing, adaptation, distribution and reproduction in any medium or format, as long as you give appropriate credit to the original author(s) and the source, provide a link to the Creative Commons licence, and indicate if changes were made. The images or other third party material in this article are included in the article's Creative Commons licence, unless indicated otherwise in a credit line to the material. If material is not included in the article's Creative Commons licence and your intended use is not permitted by statutory regulation or exceeds the permitted use, you will need to obtain permission directly from the copyright holder. To view a copy of this licence, visit http://creativecommons.org/licenses/by/4.0/ The Creative Commons Public Domain Dedication waiver (http://creativecommons.org/publicdomain/zero/1.0/) applies to the data made available in this article, unless otherwise stated in a credit line to the data. 
Conclusion: To our knowledge, this is the first systematic review in which vaccine preferences of different target groups were assessed and compared. The same attributes were most important for vaccine decisions of vaccinees and representatives, with only minor differences in level of evidence for vaccine risk and cost. Future research on vaccine preferences of health advisors and/or among target groups in low-resource settings would give insight into the generalizability of current findings.

Keywords: Discrete choice experiment, Conjoint analysis, Stated preferences, Vaccine behaviour, Vaccine decisionmaking, Target groups

\section{Background}

Within the last decades, the understanding of vaccine decision-making has been expanded. Vaccine decisions are no longer considered as simple binary decisions, but rather as complex multifaceted decisions taken along a continuum $[1,2]$. To arrive at a vaccine decision, individuals consider a set of alternatives that are evaluated based on individual needs and interests [3]. Vaccine decisions are, hence, subject to multiple internal and external stimuli, such as personal values $[4,5]$, information sources [4, 6, 7], social support [8], risk perception, vaccine effectiveness $[5,8]$ and provider trust [4-6]. As a consequence, various (possibly opposing) values may be assigned to characteristics of vaccine alternatives resulting in a wide range of vaccine preferences and decisions. Moreover, health-related preferences depend on whom it is taken for (i.e. the decision-making role) [9]. For vaccination, the decision could either be taken by the vaccinee or someone else. A vaccinee is defined as an individual to whom a vaccine is administered and who is often involved in vaccine-decision making. However, vaccinees do not necessarily need to draw the actual vaccine decision, and be the decision-maker [10].

Representatives or health advisors may also be entitled to make the decision for the vaccinee. Representatives refer to parents, guardians, relatives and others with formal authority, who decide for instance to vaccinate a child. Health advisors refer to healthcare provides or caregivers (such as family doctors) to whom decision authority is ceded by the vaccinee $[9,10]$.

A study of Goldstein \& Weber [11] indicates that individuals apply different strategies when deciding for themselves or someone else. In line with this, ZikmundFisher, Sarr, Fagerlin \& Ubel [9] demonstrate substantial variation in treatment preferences between decisionmaking roles. Medical professionals and parents are for instance more proactive in flu vaccination (i.e. choose to vaccinate) than vaccinees. Additionally, health-related preferences and decisions vary according to the importance of decisions [12]. Particularly in the context of rising vaccine opportunities, global vaccine implementation and the associated rise in vaccine decisions [13, 14], the complexity of and variation in vaccine preferences may increasingly affect vaccine uptake. Therefore, it is important to gain insight into vaccine-related behaviour including preference differences between decisionmaking groups.

With respect to preferences, a distinction is made between revealed preferences (RP) and stated preferences (SP). While RP focus on current vaccine behaviour and analyse observed choices, SP describe hypothetical vaccine decision contexts and are based on the analysis of individual choices (stated behaviour) between hypothetical alternatives. These stated choices are assumed to reflect and comply with decisions in real-life settings and are increasingly applied in health economics to understand the valuation of existing or future vaccines, to forecast (changes in) vaccine behaviour and/or to determine the willingness-to-pay (WTP) for particular alternatives [15-18]. To capture preferences in vaccination, choice-based experiments, such as Discrete Choice Experiments (DCEs) and Conjoint Analyses (CAs), are most often used [19]. Within these experiments individuals are given series of hypothetical vaccine scenarios and asked to choose their preferred scenario from a given choice set (e.g. vaccine A or B) [18]. Each scenario in a choice set is constructed by the same attributes (e.g. vaccine effectiveness, protection duration, side effects), but with varying attribute levels (e.g. effectiveness of $50 \%$ vs. $99 \%$ ). By analysing individuals' responses to changing level of attributes, attribute trade-off information is obtained and the relative importance of attributes as well as the expected vaccine uptake of current or hypothetical vaccines could be estimated [19].

Despite the growing interest in the use of choice-based experiments in vaccination, limited reviews have been conducted on this topic. Moreover, preceding reviews of SP research mainly focused on preferences for specific vaccines (e.g. HPV vaccine) and was usually restricted to High-Income Countries (HICs) [19-21]. MichaelsIgbokwe MacDonald \& Currie [19] published in 2017, for instance, a review on preferences for childhood and adolescent vaccines. However, due to their methodological focus, no conclusions were drawn on vaccine attributes influencing vaccine decisions. Furthermore, no studies nor reviews examined the differences in vaccine preferences between decision-making groups such as vaccinees and representatives. Given the global challenge 
of vaccine hesitancy [14] and limited effectiveness of policy measures fostering vaccine uptake $[22,23]$, it is important to gain deeper insight into general preferences for vaccine characteristics as well as differences in vaccine preferences. This will provide an overview of global vaccine preferences and offers the prospect of improving vaccine uptake by creating new and adapting existing policy measures and strategies to the needs of specific target groups. This approach does, hence, not only fit the life-course approach of the European Commission $[24,25]$, but also the recommendations of the Strategic Group of Experts on Immunization [14] which stressed the need to understand drivers of vaccine decisionmaking and implement tailored strategies improving vaccine uptake.

Therefore, this study aims to review, summarize and critically assess studies that used choice-based experiments to measure SP in the field of vaccination. In addition, we aimed to identify vaccine attributes influencing vaccine decision-making of specific target groups (i.e. vaccinees, representatives and health advisors) and to examine differences between vaccine preferences of target groups.

\section{Methods}

\section{Search terms and strategy}

To obtain a comprehensive overview of the current SP literature on vaccine decision-making, a systematic review was conducted. Five electronic databases were searched to identify published choice-based experiments capturing vaccine preferences. PubMed, EMBASE, Web of Science, EconLit and CINAHL were searched on the search terms: "vaccin" OR immunis" OR immuniz" AND "discrete choice OR choice experiment OR DCE OR conjoint analysis OR stated preference" AND "preference". The strategy was adapted from the review of Michaels-Igbokwe et al. [19]. Subject headings were used if applicable (MeSH terms in PubMed, Emtree terms in EMBASE and CINAHL subject headings in CINAHL). An overview of the search strategy is included in Additional file 1 . The search was limited to articles concerning human vaccines and vaccination programs. Studies who met the following inclusion criteria were included in this review: 1) describing a choice-based conjoint analysis study or a DCE; 2) targeting preferences of children, adolescents, parents, adults and/or healthcare professionals or societal preferences for attributes of vaccines or the setting; 3) original scientific research written in English. Studies without a component of choice, such as studies covering methods on time trade-off, ranking or best-worst scaling, were hence not eligible for this study. Moreover, re-analyses were excluded and duplicates were removed manually. Titles and abstracts of identified studies were then screened for relevance. Full texts of relevant studies were assessed for eligibility. Backward and forward snowballing were applied to check for additional studies [26]. Previous reviews on vaccine preferences were also checked for additional studies [17-19, 21, 27, 28]. The search was conducted between April and May 2020. An update to the review was conducted in September 2020. The PRISMA flow diagram and the PRISMA checklist were used to draw this report [29].

\section{Assessment of included studies \\ Review of study characteristics}

A standardized form was used to extract and review data from each included study. This form was in correspondence with templates used by previous reviews $[19,30]$ and covered topics related to the: a) study characteristics, b) choice task and experimental design, c) conduct, d) analysis, and e) journal and funding. As previous research [19-21] indicated that choice-based experiments use various definitions/terminology for similar attributes, attributes were first divided into four overarching categories: outcomes, process, cost and other. 'Outcomes' referred to the results or consequences of administering vaccines. 'Process' incorporated the activities related to the delivery and administration of vaccines and 'cost' covered the (financial) costs of vaccines. Attributes that could not be grouped under the former three were classified into the category 'other'. Within all four categories, attributes with shared features were then grouped according to their underlying concept. These groups of attributes were called 'domains' and can be regarded as subgroups which allowed a more comprehensive synthesis of results. Data was extracted from full text articles and corresponding supplementary material that was available online. The search, data extraction, review of study characteristics, quality assessment and data comparison were conducted by one reviewer (MD). Eligibility of ambiguous studies and study characteristics were discussed with a second researcher (IvdP). Atlas.ti (version 8.4.4) and spreadsheets of MS Excel were used for the data extraction and quality assessment.

\section{Assessment of quality}

Prior to the data comparison, the methodological quality of included studies was critically appraised by using the 13-criteria-checklist of Mandeville Lagarde \& Hanson [30], which incorporates all key stages DCEs: choice task design, experimental design, conduct and analysis. Full texts of included studies were appraised by allocating scores to each criterion of the checklist. Three answer options (scores) were possible and depended on the presence of items. A score of 0 was assigned to items that were not satisfied, absent or not reported, 0.5 to items that were partly present or satisfied and 1 to items that were present or satisfied $[19,30]$. The maximum 
score was 13 and was associated with a high methodological quality. Accordingly, the minimum score of 0 indicated a low methodological quality. As recommended by the developers of the checklist [30], the quality threshold of $75 \%$ was used. A quality score of at least 10 (out of 13) was considered sufficient to be included in the data comparison.

\section{Data comparison}

A descriptive synthesis was used to indicate the relative importance of individual vaccine attributes for specific target groups. The amount of times that particular vaccine attributes (domains) were reported in studies were counted as well as the amount of times domains were reported statistically significant by the authors (incl. $p$ value threshold or alpha). Main models and overall results were used if available. Subgroup results were used when outcomes were reported for subgroups/classes only (i.e. no overall data). If a study included multiple attributes related to the same domain (e.g. 'vaccine side effects' and 'risk of dosing' both targeting the domain 'vaccine risk'), statistical significance was reported for each of the attributes separately. This implies that a study could report statistical significance for a single domain more than once. To ensure a more accurate reflection of domains driving decision-making, the amount of studies reporting statistical significance, for a particular domain, were also stated. If no $p$-value threshold was reported but $p$-values were given, the commonly used threshold of $p<0.05$ was used [31]. The overall frequency as well as the classification of statistically significant attributes/domains were presented in a tabular summary and were reported for each target group [32].

\section{Comparison of high- and lower-quality studies}

To determine whether exclusion of lower-quality studies changed findings for any of the target groups (i.e. inferred selection bias), results of only including highquality studies (quality score $\geq 10$ ) were compared to results of including all eligible studies (quality score 0-13). Face validity was used to determine if and to what extend results were in accordance with each other.

\section{Ethics}

Before the start of the study, a review protocol was submitted on PROSPERO (ID: 178245). The review was executed as planned/described. No ethical approval of a Medical Review Ethics Committee was needed [33].

\section{Results}

\section{Search results}

In total, 546 records were identified during the primary search. After removal of duplicates, 416 unique records were screened on title and abstract. This resulted in a further removal of 364 records, after which 52 remained left for full-text screening. Reason for removal related to the inappropriateness of the study design, study topic, type of publication (e.g. re-analysis, meeting/conference abstract, erratum) or a combination. During the subsequent searches, two additional articles were obtained (one through snowballing, one through search update). A total of 42 articles were eligible and were included in the review of study characteristics. In addition, 26 articles did not pass the quality assessment as their score was below 10 (see validity assessment). Eventually, sixteen articles were included in the data comparison (Fig. 1).

\section{Review of study characteristics}

Characteristics of all 42 studies were described in this section in order to provide a full overview of the current SP literature on vaccine preferences. A more detailed summary of study characteristics is presented in Additional file 2.

\section{General study characteristics}

General characteristics of the 42 included studies can be found in Tables 1 and 2. Most choice-based experiments applied a DCE or CA format (resp. 73.8 and 23.8\%). The majority of the studies $(n=37)$ were published after 2010: nineteen (45.2\%) between 2011 and 2015 and eighteen (42.9\%) between 2016 and September 2020 (Table 1). Included studies were conducted in twenty countries mainly spread across Europe $(n=25)$, Asia $(n=11)$ and North America $(n=8)$ (Table 2). More than $80 \%$ was conducted in HICs $(n=34)$. Choice experiments were least performed upper and Low-MiddleIncome Countries (LMICs). Fourteen existing vaccines or vaccine programs were studied, most commonly HPV and influenza vaccines (Table 2). Vaccine programs referred either to the administration of a course of vaccines (e.g. all childhood vaccines) or to combination vaccines (e.g. Tdap). Preferences of representatives were most often studied $(47.6 \%$, Table 1$)$. This target group usually referred to (expectant) parents, guardians or caregivers $(n=19)$, in particular mothers of children aged below $5(n=9)$. Vaccinees were targeted in a third of the studies (35.7\%). They either focused on the (general) adult population $(n=7)$ or children/adolescents $(n=6)$, especially teenage girls. Preferences of health advisors such as paediatricians were least captured among included studies $(9.5 \%$, Table 1$)$. The variety of objectives reported in studies is presented in Table 1.

\section{Choice task}

The number of choice tasks ranged from four to 36, with most studies (40.5\%) including less than ten choice tasks (Table 3). Ten studies (23.8\%) used one method to 


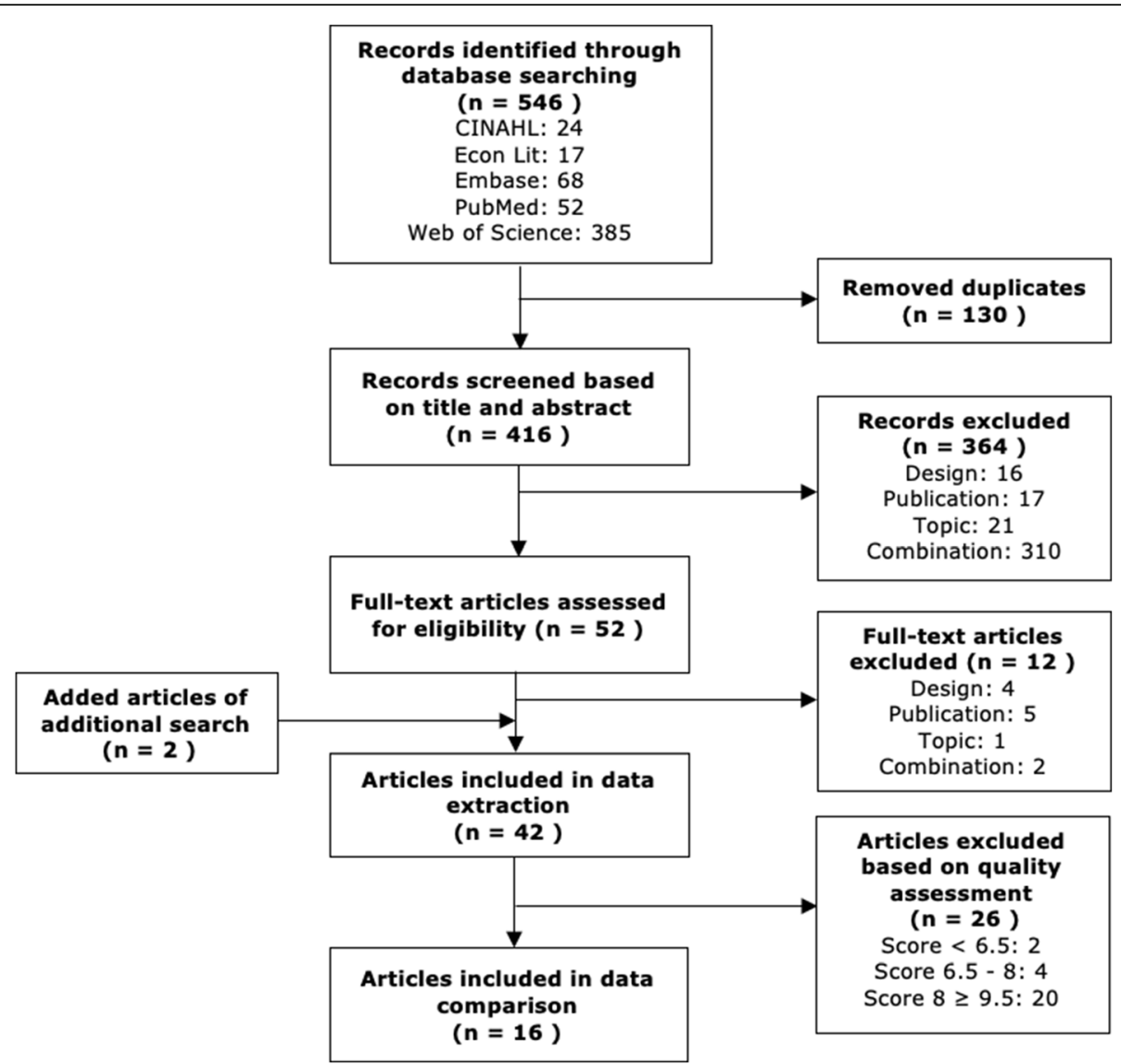

Fig. 1 PRISMA flow diagram of choice-based experiments capturing vaccine preferences

identify appropriate attributes and levels, while 31 (73.8\%) used more than one method listed in Table 3. Literature reviews and qualitative research such as focus groups were most popular (Table 3). Nearly all studies (92.9\%) presented two or more vaccine scenarios per choice task and used a multinomial choice structure. Among these studies $(n=39)$, D-efficiency was most often used to pair and group choice profiles (35.9\%). In addition, choice questions were mainly unforced and an option to remain undecided (opt-out) was provided (51.3\%) (Table 3). Multiple descriptions were used to indicate the opt-out alternative (e.g. 'no vaccination', 'neither'). Sixteen studies (41.1\%) forced respondents to choose between two vaccine scenarios, the majority of them $(n=12)$ provided an opt-out in second instance (two-stage choice). Respondents were for instance asked if they would make the same choice in real life [34]. Two studies $[35,36]$ reported different formats in main texts and example questions.

\section{Experimental design}

An overview of the experimental designs used across studies is presented in Table 4. A fractional factorial design was used in 35 studies (83.3\%). Only one study (2.4\%) used all possible combinations (full factorial design). Among the studies reporting their type of design $(n=36)$, a range of software packages was used, with Ngene being most popular (25.0\%). Eight studies (22.2\%) used approaches other than software such as a catalog or a manual approach. Studies that included interaction terms along with main effects $(n=23)$ generally used more choice tasks than the studies analysing main effects only $(n=2)$. Although seventeen studies $(40.5 \%)$ did not provide details on their design plan in the main text, primary analyses of thirteen studies showed that it was restricted to main effects (Table 4).

In total 226 vaccine attributes were included in the 42 choice experiments. The number of attributes per study ranged from three to eight, the number of levels per attribute ranged from two to seven. With regard to the overarching categories, $38.9 \%$ of the attributes were categorized as outcome, $24.8 \%$ as process, $23.0 \%$ as other and $13.3 \%$ as cost. Overall, eighteen domains were identified (3 outcome, 8 process, 1 cost, 7 other). Details on the categories and domains are delineated in the data comparison sections (Tables 7 and 8) and in Additional file 3. 
Table 1 General study characteristics of included studies

\begin{tabular}{|c|c|c|}
\hline Aspect & Specification & Number of studies (\%) \\
\hline \multirow[t]{3}{*}{ Choice based experiment } & ADCE & $1(2.4)$ \\
\hline & CA & $10(23.8)$ \\
\hline & DCE & $31(73.8)$ \\
\hline \multirow[t]{4}{*}{ Year of publication } & $2000-2005$ & $2(4.8)$ \\
\hline & $2006-2010$ & $3(7.1)$ \\
\hline & $2011-2015$ & $19(45.2)$ \\
\hline & 2016-2020 (September) & $18(42.9)$ \\
\hline \multirow[t]{4}{*}{ Target group ${ }^{a}$} & Health advisors & $4(9.5)$ \\
\hline & Representatives & $20(47.9)$ \\
\hline & Vaccinees & $15(35.7)$ \\
\hline & Vaccinees \& representatives & $3(7.1)$ \\
\hline \multirow[t]{10}{*}{ Objective $^{b}$} & Assess preferences vaccines, vaccine attributes, vaccine programs & $36(85.7)$ \\
\hline & Compare individual DCE & $1(2.4)$ \\
\hline & Compare RP with SP & $1(2.4)$ \\
\hline & Estimate WTP & $15(35.7)$ \\
\hline & Explore variation in preferences across groups & $8(19.0)$ \\
\hline & External factors influencing preferences & $6(14.3)$ \\
\hline & Identify reason(s) not to vaccinate & $1(2.4)$ \\
\hline & Predict vaccine uptake/coverage & $11(26.2)$ \\
\hline & Policy recommendations design and/or communication of vaccine programs/strategies & $10(23.8)$ \\
\hline & Trade-off vaccine attributes & $6(14.3)$ \\
\hline
\end{tabular}

${ }^{\mathrm{a}}$ Due to rounding of percentages, the total may not count up to $100 \%$; ${ }^{\mathrm{b}} \mathrm{As} 32$ studies included more than objective, the total number of studies exceeds the total amount of included studies (and 100\%)

\section{Conduct}

More than $80 \%$ of the studies reported a pilot and/or soft launch (Table 4). The size differed from four [37] to three hundred respondents [38] and from a single-stage [35] to multiple-stage procedures (e.g. combination of pre-pilot, pilot and soft launches) [39, 40]. The majority of self-administered surveys was completed online (25 studies). Sample sizes ranged from fifty [41] to 2505 respondents [42]. Most studies included between two and four hundred respondents (Table 4). Larger sample sizes were not necessarily accompanied by the use of stricter thresholds (e.g. $p<0.001$ ). The rule of thumb proposed by Orme [43] was most often used to justify sample sizes of CAs. Half of the studies did not justify their sample size nor included sample size calculations (Table 4). A third of the studies (35.7\%) compensated respondents in cash, vouchers or a physical gift, the value varied from $£ 1-2$ to $\$ 55$ (Table 4).

\section{Analysis}

A summary of the approaches used to analyse data is presented in Table 5. Half of the studies applied mixed or random parameter logit models (MXL/RPL). Random or mixed effects logit models were most often used to analyse forced choices. Nearly all studies (97.6\%) accounted for variation in preferences across groups. Subgroup analyses were either performed by using separate models for different groups or by incorporating interaction terms into the model. The methods used to distinguish subgroups are outlined in Table 5. Methodological aims drove the subgroup analyses of 29 studies. These studies used for instance different cost ranges for subgroups or compared groups who passed and failed the consistency/dominance tests and groups with and without preference to opt-out. With regard to the outcome measures, welfare measures such as WTP were most frequently used (45.2\%), followed by probability or uptake analyses (42.9\%). Least reported measures were market simulations, willingness-to-accept and positive or predictive value (see 'other measures' Table 5). Most studies $(83.3 \%)$ used software to analyse the data. These packages were not necessarily the same as the ones used to construct experimental designs (e.g. Ngene vs. Nlogit in Hofman et al. [44]).

\section{Journal \& funding}

The majority of the studies (59.5\%) were published in clinical journals (Table 5). Of the 39 studies reporting their source of funding, approximately a quarter was funded or supported by a pharmaceutical or 
Table 2 Number of studies per country and vaccine type

\begin{tabular}{|c|c|c|c|}
\hline Country & Number of studies (\%) ${ }^{a}$ & Type of vaccine & Number of studies (\%) ${ }^{\mathrm{a}}$ \\
\hline Australia & $3(7.1)$ & Childhood (combination) vaccines & $6(14.3)$ \\
\hline Belgium & $1(2.4)$ & General vaccines & $3(7.1)$ \\
\hline Canada & $1(2.4)$ & Hepatitis B (HepB) vaccine & $2(4.8)$ \\
\hline China & $3(7.1)$ & Herpes zoster vaccine & $1(2.4)$ \\
\hline Europe (not specified) & $1(2.4)$ & Human Papilloma Virus (HPV) vaccine & $9(21.4)$ \\
\hline France & $2(4.8)$ & Hypothetical vaccine & $5(11.9)$ \\
\hline Germany & $3(7.1)$ & Influenza vaccine & $8(19.0)$ \\
\hline Hong Kong & $3(7.1)$ & Leptospirosis vaccine & $1(2.4)$ \\
\hline Hungary & $1(2.4)$ & Meningococcal (B) vaccine & $3(7.1)$ \\
\hline Italy & $1(2.4)$ & Pertussis vaccine & $1(2.4)$ \\
\hline Japan & $2(4.8)$ & Pneumococcal vaccine & $1(2.4)$ \\
\hline Netherlands, the & $9(21.4)$ & Rotavirus vaccine & $2(4.8)$ \\
\hline Philippines, the & $1(2.4)$ & Tetanus-Diphtheria-Pertussis (Tdap) vaccine & $1(2.4)$ \\
\hline Poland & $2(4.8)$ & Travel vaccines & $1(2.4)$ \\
\hline South-Africa & $1(2.4)$ & Varicella vaccine & $1(2.4)$ \\
\hline Spain & $2(4.8)$ & & \\
\hline Sweden & $1(2.4)$ & & \\
\hline Thailand & $1(2.4)$ & & \\
\hline United Kingdom & $2(4.8)$ & & \\
\hline Unites States of America & $7(16.7)$ & & \\
\hline Vietnam & $1(2.4)$ & & \\
\hline
\end{tabular}

${ }^{a}$ As four studies included more than one country and one study covered multiple vaccines, the total number of studies exceeds the total amount of included studies (and 100\%)

manufacturing company producing the vaccine under study $(n=11)$. The remaining studies, except for Ngorsuraches et al. [45], received a research grant of governmental bodies, non-profit organizations or research/ education institutes (Table 5).

\section{Quality assessment}

An overview of the quality scores of all 42 studies is presented in Table 6. Quality scores ranged from 5.5 to 12.5, with an average score of 9.3. Scores did not improve over time, since average scores of studies published between 2000 and 5, 2006-10, 2011-5 and 2016-20 were $8.8,10.5,9.1$ and 9.4 respectively. However, industry-funded studies scored lower than nonindustry funded studies (mean of resp. 8.5 and 9.5). Among the four categories distinguished in Table 6, studies scored best on analysis (mean: 0.84), followed by choice task design (mean: 0.70), conduct (mean: 0.65) and experimental design (mean: 0.55).

With respect to the category choice task design, the majority of the studies used unidimensional attributes and included an opt-out in first or second instance (resp. 71.4 and 73.8\%). Weaknesses were particularly observed in the identification of attributes/levels and in the occurrence of conceptual overlap between attributes. The second category, experimental design, was comprised of one criterion. The majority of the studies (64.3\%) used (fractional) factorial designs that were sub-optimal (i.e. scored below 1). Furthermore, varying scores were administered on the criteria of the conduct category. While studies commonly tested survey features in a pilot and identified appropriate target populations, three-quarter reported response rates below $50 \%$ and almost half used inappropriate sampling frames. Almost all studies satisfied at least three of the four criteria incorporated in the last category analysis, particularly the ones concerning the economic model and use of a common comparable scale (metric) to interpret relative attribute effects [77, 78]. Some improvements could still be made in analysis of preferences of heterogenous populations, as pooled data might cover up preference differences between subgroups [30,77].

When combining scores on the four categories into an overall score, sixteen of the 42 studies (38.1\%) had a total score of at least 10 and passed the quality assessment (Fig. 1). These were regarded as 'high-quality studies' and were included in the data comparison. Total 
Table 3 Overview of the design of the choice tasks among included studies

\begin{tabular}{|c|c|c|}
\hline Aspect & Specification & $\begin{array}{l}\text { Number of studies } \\
\text { (\%) }\end{array}$ \\
\hline \multirow[t]{8}{*}{ Methods to identify attributes $^{a}$} & Characteristics vaccine, disease & $2(4.8)$ \\
\hline & Expert consultation & $19(45.2)$ \\
\hline & Literature review & $33(78.6)$ \\
\hline & Previous DCE & $4(9.5)$ \\
\hline & Qualitative research & $28(66.7)$ \\
\hline & Theories vaccine decision-making & $1(2.4)$ \\
\hline & Vaccination policy & $1(2.4)$ \\
\hline & Not reported & $1(2.4)$ \\
\hline \multirow[t]{2}{*}{ Choice structure } & Binary & $3(7.1)$ \\
\hline & Multinomial & $39(92.9)$ \\
\hline \multirow{7}{*}{$\begin{array}{l}\text { Methods to create choice sets, of multinomial studies }(n= \\
39)^{a}\end{array}$} & D-efficiency & $3(7.7)$ \\
\hline & D-efficiency using software & $11(28.2)$ \\
\hline & Fold-over & $3(7.7)$ \\
\hline & Random & $3(7.7)$ \\
\hline & Random using software & $1(2.6)$ \\
\hline & Other software & $5(12.8)$ \\
\hline & Not reported & $13(33.3)$ \\
\hline \multirow[t]{5}{*}{ Format of choice question, of multinomial studies $(n=39)^{b}$} & Forced choice & $4(10.3)$ \\
\hline & Forced choice, followed by opt-out & $12(30.8)$ \\
\hline & Unforced choice with opt-out & $18(46.2)$ \\
\hline & $\begin{array}{l}\text { Unforced choice with opt-out, followed by forced } \\
\text { choice }\end{array}$ & $2(5.1)$ \\
\hline & Unclear & $3(7.7)$ \\
\hline \multirow[t]{4}{*}{ Number of choice tasks } & $<10$ & $17(40.5)$ \\
\hline & $10-15$ & $10(23.8)$ \\
\hline & $>15$ & $10(23.8)$ \\
\hline & Not reported & $5(11.9)$ \\
\hline
\end{tabular}

${ }^{\mathrm{a} A s}$ multiple methods could be used to identify attributes, the total number of studies exceeds the total amount of included studies (and $\left.100 \%\right) ;{ }^{\mathrm{b}}$ Note the proportion (\%) is calculated from studies applying multinomial choice structures $(n=39)$, not from the total amount of studies $(n=42)$

scores of the remaining studies $(61.9 \%)$ were insufficient to exclude most threats to validity $($ score $<10)$. These 'lower-quality studies' were hence only included in the robustness analyses. A more detailed description of the quality assessment is enclosed in Additional file 4.

\section{Comparison of high-quality studies}

Of the sixteen high-quality studies, seven focused on vaccinees $(43.8 \%)$, six on representatives $(37.5 \%)$ and one on health advisors $(6.3 \%)$. As it is difficult to draw firm conclusions on a single study, the study on health advisors [65] was added to the representatives' category. Two studies [42, 74] addressed vaccinees as well as representatives (12.5\%). As both reported preferences for vaccinees and representatives separately (per class), classes covering vaccinees were incorporated into the analysis of vaccinees and classes covering representatives into the analysis of representatives. Therefore, data of nine studies was compared for both target groups. Information on vaccine attributes of high-quality studies is summarized in Additional file 5.

\section{Vaccinees}

Studies capturing preferences of vaccinees used 48 attributes, of which $50 \%$ were classified as outcome, $16.7 \%$ as process, $10.4 \%$ as cost and the remaining $22.9 \%$ as other. Thirteen domains were identified in total (three outcome, four process, one cost and five other). Figure 2 presents the total amount of attributes incorporated in each category and domain. Importance rankings derived from this figure are outlined in Additional file 6. Most frequently used outcome measures were vaccine 
Table 4 Overview of the experimental design and conduct of included studies

\begin{tabular}{|c|c|c|}
\hline Aspect & Specification & $\begin{array}{l}\text { Number of studies } \\
(\%)^{\mathbf{b}}\end{array}$ \\
\hline \multirow[t]{3}{*}{ Type of design } & Fractional factorial design & $35(83.3)$ \\
\hline & Full factorial design & $1(2.4)$ \\
\hline & Not reported & $6(14.3)$ \\
\hline \multirow[t]{5}{*}{ Design plan } & Main effects & $2(4.8)$ \\
\hline & Main and interaction effects & $23(54.8)$ \\
\hline & Not reported, main effects in primary analysis & $13(31.0)$ \\
\hline & $\begin{array}{l}\text { Not reported, main \& interaction effects in primary } \\
\text { analysis }\end{array}$ & $1(2.4)$ \\
\hline & Not reported, unclear in analysis & $3(7.1)$ \\
\hline \multirow{9}{*}{$\begin{array}{l}\text { Software/approach, of studies reporting type of design }(n= \\
36)^{\mathrm{a}}\end{array}$} & Ngene & $9(25.0)$ \\
\hline & SAS & $3(8.3)$ \\
\hline & Sawtooth & $3(8.3)$ \\
\hline & SPSS & $2(5.6)$ \\
\hline & Other computer algorithm & $3(8.3)$ \\
\hline & Catalog approach & $5(13.9)$ \\
\hline & Manual & $1(2.8)$ \\
\hline & Other approach & $2(5.6)$ \\
\hline & Not reported & $8(22.2)$ \\
\hline \multirow[t]{3}{*}{ Piloting } & Yes & $34(81.0)$ \\
\hline & No & $1(2.4)$ \\
\hline & Not reported & $7(16.7)$ \\
\hline \multirow[t]{4}{*}{ Mode of administration } & Interview-administered & $5(11.9)$ \\
\hline & Self-administered & $34(81.0)$ \\
\hline & Both & $1(2.4)$ \\
\hline & Not reported & $2(4.8)$ \\
\hline \multirow[t]{7}{*}{ Sample size } & $<200$ & $1(2.4)$ \\
\hline & $200-400$ & $14(33.3)$ \\
\hline & $400-600$ & $12(28.6)$ \\
\hline & $600-800$ & $6(14.3)$ \\
\hline & $800-1000$ & $2(4.8)$ \\
\hline & $1000-1200$ & $1(2.4)$ \\
\hline & $\geq 1200$ & $6(14.3)$ \\
\hline \multirow[t]{3}{*}{ (Financial) compensation } & Yes & $15(35.7)$ \\
\hline & No & $2(4.8)$ \\
\hline & Not reported & $25(59.5)$ \\
\hline
\end{tabular}

${ }^{a}$ Note that the proportion of the studies using particular software packages or approaches is taken from the studies reporting their type of design ( $n=36$ ) instead of all includes studies $(n=42)$; ${ }^{\text {b }}$ Due to rounding of percentages, the total may not count up to $100 \%$

effectiveness and vaccine risk (both 18.8\%), followed by protection duration (12.5\%) and cost (10.4\%). Vaccine effectiveness referred to the level of protection that a vaccine provided against a disease or to the deaths/illnesses prevented over a certain time span. Vaccine risk referred to the frequency of (mild or serious) side effects after vaccination. Context, information, other disease related factors, vaccine advice/support were also reported, but could not be grouped in any of the three categories. They are classified as other. 'Context' referred to vaccine coverage rates at local and population level, 'information' to the media coverage or attention about the vaccine and 'vaccine advice/support' to recommendations of family, friends, doctors, governmental bodies and international organizations. Process-related domains were least reported. Vaccine accessibility was for instance only 
Table 5 Overview of approaches used to analyse data, the journal and source of funding

\begin{tabular}{|c|c|c|}
\hline Aspect & Specification & Number of studies (\%) ${ }^{\mathrm{a}}$ \\
\hline \multirow[t]{14}{*}{ Econometric model Subgroup analysis } & Multinomial logit & $12(28.6)$ \\
\hline & Generalized linear random effects logit & $1(2.4)$ \\
\hline & Hierarchical Bayes & $6(14.3)$ \\
\hline & Latent class & $4(9.5)$ \\
\hline & Random effects logit & $6(14.3)$ \\
\hline & Mixed logit (random parameter) & $21(50.0)$ \\
\hline & Other & $5(11.9)$ \\
\hline & Methodology related & $29(69.0)$ \\
\hline & Previous experiences & $5(11.9)$ \\
\hline & Sociodemographic factor(s) & $32(76.2)$ \\
\hline & Vaccine beliefs/perception/knowledge & $13(31.0)$ \\
\hline & Vaccine intention or behaviour & $6(14.3)$ \\
\hline & Vaccination or health status & $5(11.9)$ \\
\hline & Other & $5(11.9)$ \\
\hline \multirow[t]{7}{*}{ Outcome measure } & Individual utility scores & $3(7.1)$ \\
\hline & Odds ratio, change in log-odds & $8(19.0)$ \\
\hline & Relative attribute importance & $10(23.8)$ \\
\hline & Marginal rate of substitution (trade-off) & $8(19.0)$ \\
\hline & Vaccine uptake/probability analysis & $18(42.9)$ \\
\hline & WTP & $19(45.2)$ \\
\hline & Other & $4(9.5)$ \\
\hline \multirow[t]{8}{*}{ Analysis software } & JMP Pro & $2(4.8)$ \\
\hline & Nlogit & $9(21.4)$ \\
\hline & SAS & $11(26.2)$ \\
\hline & Sawtooth & $4(9.5)$ \\
\hline & SPSS & $3(7.1)$ \\
\hline & Stata & $11(26.2)$ \\
\hline & Other & $10(23.8)$ \\
\hline & Not reported & $7(16.7)$ \\
\hline \multirow[t]{6}{*}{ Journal } & Clinical & $25(59.5)$ \\
\hline & Economic & $6(14.3)$ \\
\hline & General & $4(9.5)$ \\
\hline & Marketing & $1(2.4)$ \\
\hline & Methodological & $1(2.4)$ \\
\hline & Pharmaceutical & $1(2.4)$ \\
\hline \multirow[t]{3}{*}{ Funding $^{b}$} & Yes Industry-funded & $11(28.2)$ \\
\hline & Non-industry-funded & $27(69.2)$ \\
\hline & No & $1(2.6)$ \\
\hline
\end{tabular}

${ }^{a}$ Totals exceed the total number of studies included in this review, since 13/42 studies used more than one econometric model, $28 / 42$ used more than one approach to identify subgroups, $23 / 42$ used more than one outcome measure, 10/42 used more than one software package; ${ }^{b}$ Note, the source of funding is based on the studies reporting their source of funding $(n=39)$ instead of all includes studies $(n=42)$

included in the study of Verelst, Willem, Kessels \& Beutels $(2.1 \%)$ [74]. Statistical significance was reported in all nine studies. The average sample size was 1113 and three $p$-value thresholds were used to determine if attributes were statistically significant (Table 7). Vaccine risk and vaccine effectiveness, both outcome measures, were most often statistically significant (resp. 15 and 14 times). However, the latter was not found to be 


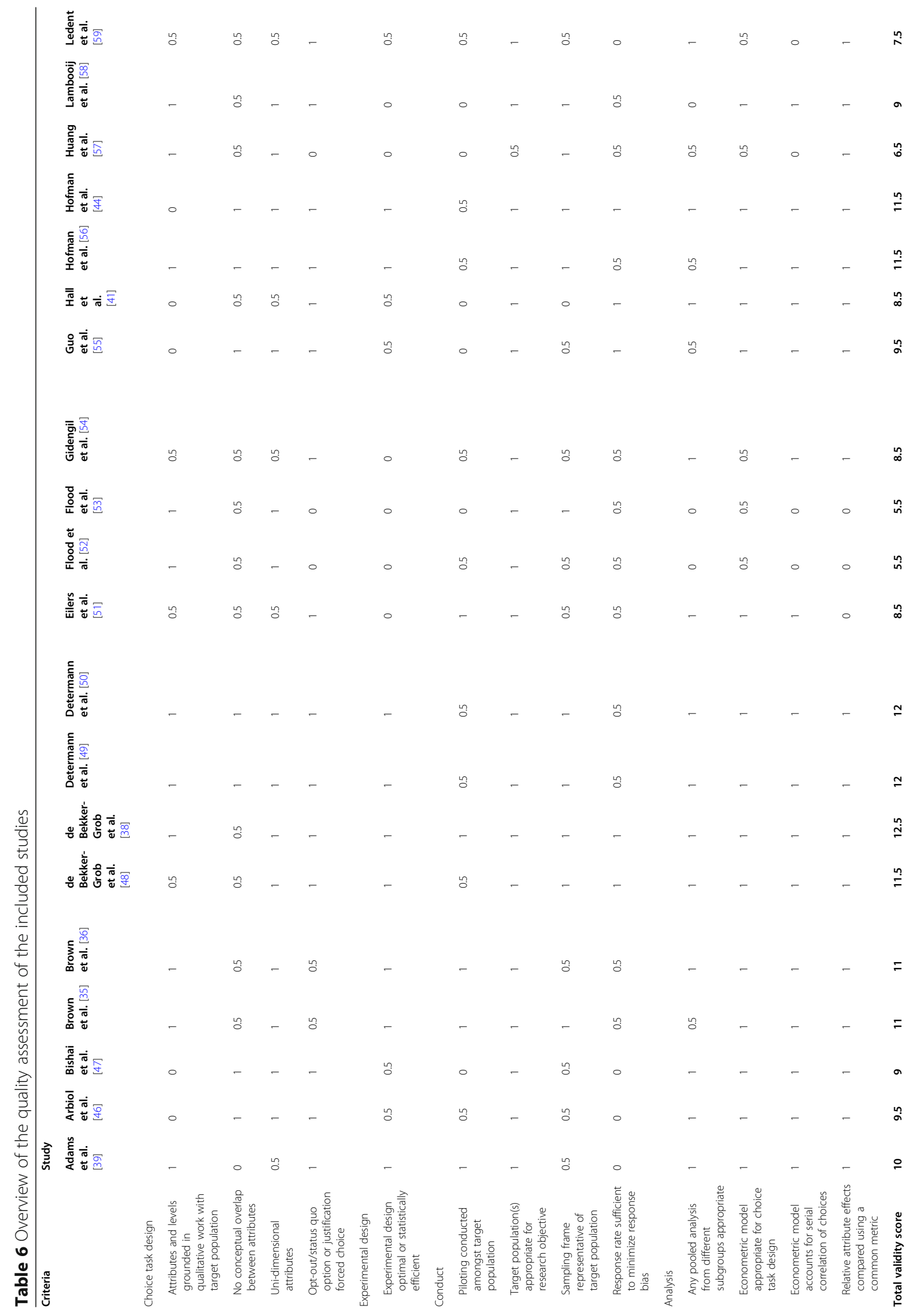




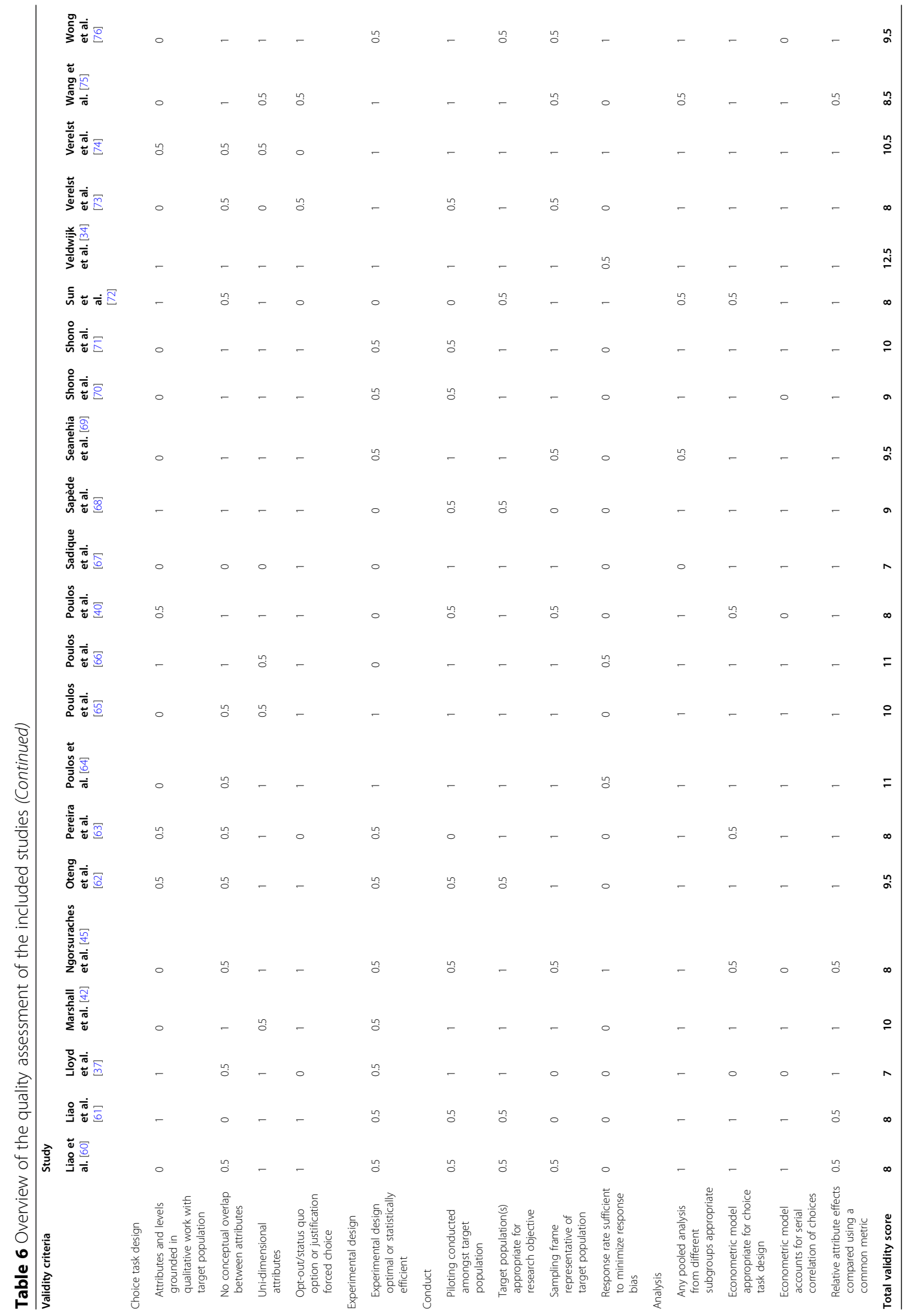




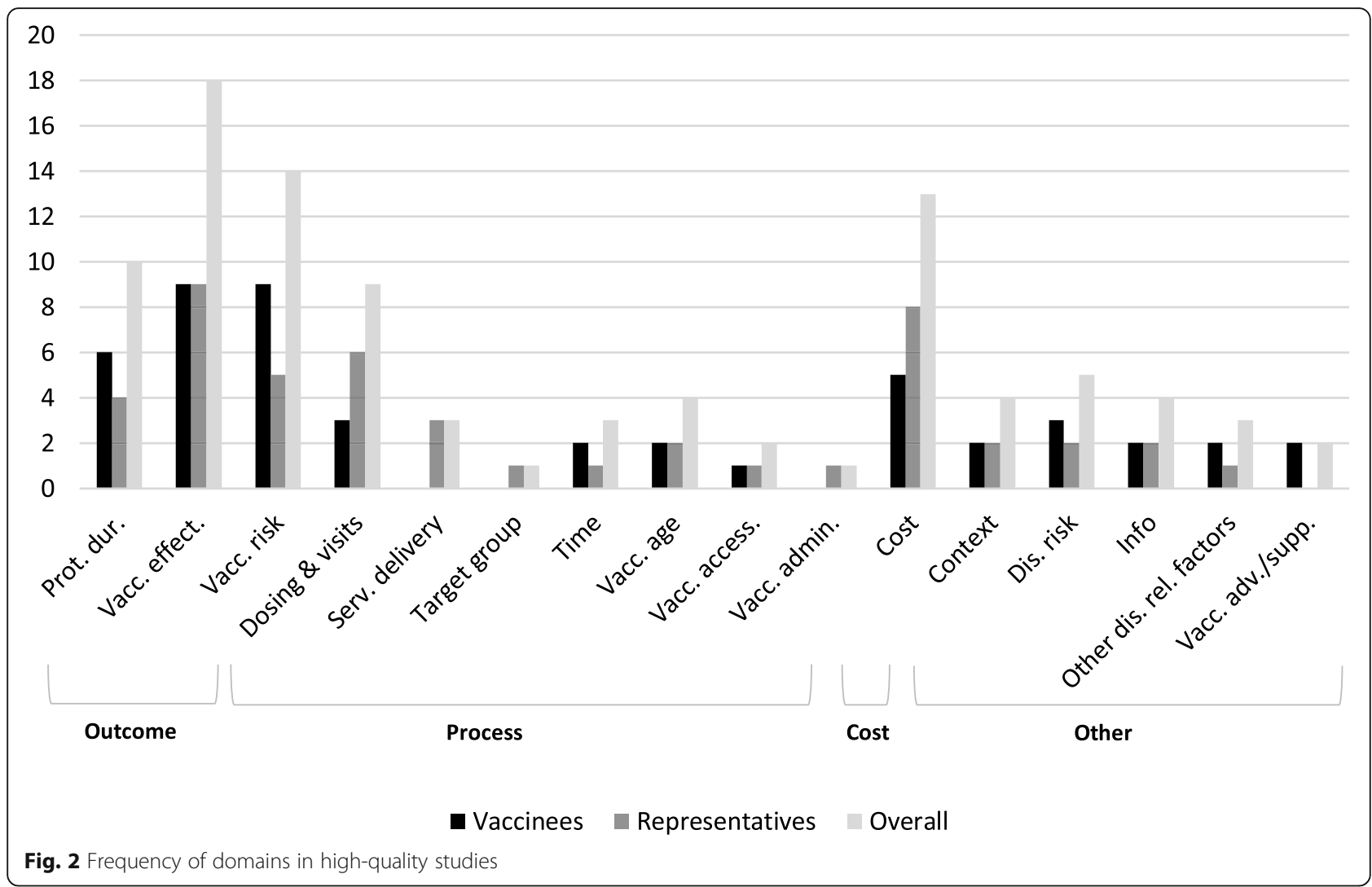

significant for one class of the study of Determann et al. [50]. Domains that were also commonly statistically significant included: cost, protection duration, dosing \& visits, information and vaccine advice or support (Table 7). The importance of the former three was also confirmed in the frequency of reporting (Fig. 2). Factors other than disease risk, such as the spread of the disease and availability of curative treatments, were grouped under the domain 'other disease related factors' (other). This domain as well as the domain 'time' (process) were not statistically significant in any of the studies (Table 7).

\section{Representatives}

In total, 48 attributes were identified in nine studies capturing vaccine preferences of representatives (Fig. 2). Of these attributes, $37.5 \%$ were outcome-related, $31.3 \%$ were process-related and $16.7 \%$ were cost-related. The remaining $11.6 \%$ of the attributes were categorized as other. Overall, fifteen domains were identified (three outcome, seven process, one cost, four other). In contrast to vaccinees, attributes regarding vaccine advice or support were not reported. However, three process-related domains were added: service delivery, target group and vaccine administration. 'Service delivery' covered practical aspects such as vaccine location and availability of appointments, while 'vaccine administration' referred to the mode of administration (e.g. injection). Vaccine effectiveness was most frequently reported $(18.8 \%)$, followed by cost (16.7\%), dosing \& visits (12.5\%), vaccine risk (10.4\%) and protection duration (8.3\%). In line with studies targeting vaccinees, vaccine accessibility was least reported. Two studies $[65,66]$ did not report statistical significance or did not provide a legend (description). For the study of Shono \& Kondo [71], statistical significance could be determined based on reported $p$-values. Therefore, seven studies were included in Table 8. On average 1037 respondents were included and among the four thresholds used, $p<0.05$ was most commonly applied. All attributes included in high-quality studies were statistically significant in one or more study/studies (Table 8). In line with the frequency of reporting, vaccine effectiveness and cost were most commonly statistically significant, followed by vaccine risk and protection duration. Domains that were least used were also least reported statistically significant (Table 8). These were categorized as process and other. Varying results were reported for information (other) and service delivery (process) (Table 8). The professional administering vaccines was for instance statistically significant, while the availability of appointments and location were not [39]. Information was found to be statistically significant half of the times, as information on benefits and risks were statistically significant, but the format was not [39]. 
Table 7 Overview of high-quality studies reporting relative statistical significance (vaccinees)

\begin{tabular}{|c|c|c|c|c|c|}
\hline \multirow[t]{2}{*}{ Category \& domain $(n=)^{*}$} & \multicolumn{5}{|c|}{ Statistical significance ${ }^{* *}$} \\
\hline & $P<0.10$ & $P<0.05$ & $P<0.01$ & Total & Not significant \\
\hline \multicolumn{6}{|l|}{ Outcome } \\
\hline Protection duration $(n=6)$ & 0 & 3 & 5 & 8 & 1 \\
\hline Vaccine effectiveness $(n=8)$ & 0 & 5 & 9 & 14 & 1 \\
\hline Vaccine risk $(n=7)$ & 0 & 4 & 11 & 15 & 0 \\
\hline \multicolumn{6}{|l|}{ Process } \\
\hline Dosing \& visits $(n=3)$ & 1 & 1 & 3 & 5 & 1 \\
\hline Time $(n=2)$ & 0 & 0 & 0 & 0 & 2 \\
\hline Vaccination age $(n=2)$ & 0 & 1 & 2 & 2 & 1 \\
\hline Vaccine accessibility $(n=1)$ & 0 & 1 & 0 & 1 & 0 \\
\hline \multicolumn{6}{|l|}{ Cost } \\
\hline Cost $(n=5)$ & 0 & 1 & 8 & 9 & 0 \\
\hline \multicolumn{6}{|l|}{ Other } \\
\hline Context $(n=1)$ & 0 & 2 & 0 & 2 & 0 \\
\hline Disease risk $(n=2)$ & 0 & 1 & 2 & 3 & 0 \\
\hline Information $(n=2)$ & 1 & 1 & 3 & 5 & 0 \\
\hline Other disease related factors $(n=1)$ & 0 & 0 & 0 & 0 & 2 \\
\hline Vaccine advice/support $(n=2)$ & 1 & 0 & 4 & 5 & 0 \\
\hline
\end{tabular}

${ }^{*} n=$ number of studies reporting domains. All nine studies reported statistical significance; ** Information is based on main models and pooled data when available (if not, data of separate models/classes wasused). Some studies included more than one attribute related to a particular domain. Totals could hence exceed the total number of studies incorporated.

Table $\mathbf{8}$ Overview of high-quality studies reporting relative statistical significance (representatives)

\begin{tabular}{|c|c|c|c|c|c|c|}
\hline \multirow[t]{2}{*}{ Category \& domain $(n=)^{*}$} & \multicolumn{6}{|c|}{ Statistical significance ${ }^{* *}$} \\
\hline & $P<0.10$ & $P<0.05$ & $P<0.01$ & $P<0.001$ & Total & Not significant \\
\hline \multicolumn{7}{|l|}{ Outcome } \\
\hline Protection duration $(n=4)$ & 0 & 1 & 2 & 1 & 4 & 1 \\
\hline Vaccine effectiveness $(n=6)$ & 0 & 3 & 3 & 1 & 7 & 0 \\
\hline Vaccine risk $(n=5)$ & 1 & 4 & 0 & 0 & 5 & 0 \\
\hline \multicolumn{7}{|l|}{ Process } \\
\hline Dosing \& visits $(n=2)$ & 0 & 1 & 1 & 0 & 2 & 0 \\
\hline Service delivery $(n=2)$ & 0 & 1 & 0 & 0 & 1 & 2 \\
\hline Target group $(n=1)$ & 0 & 0 & 1 & 0 & 1 & 0 \\
\hline Time $(n=1)$ & 0 & 0 & 1 & 0 & 1 & 0 \\
\hline Vaccination age $(n=1)$ & 0 & 1 & 0 & 0 & 1 & 0 \\
\hline Vaccine accessibility $(n=1)$ & 0 & 1 & 0 & 0 & 1 & 0 \\
\hline \multicolumn{7}{|l|}{ Cost } \\
\hline Cost $(n=5)$ & 0 & 1 & 4 & 1 & 6 & 0 \\
\hline \multicolumn{7}{|l|}{ Other } \\
\hline Context $(n=1)$ & 0 & 2 & 0 & 0 & 2 & 0 \\
\hline Disease risk $(n=1)$ & 0 & 1 & 0 & 0 & 1 & 0 \\
\hline Information $(n=1)$ & 0 & 0 & 1 & 0 & 1 & 1 \\
\hline
\end{tabular}

${ }^{*} n=$ number of studies reporting domains. 7/9 studies reported statistical significance (incl. legend) and/or $p$-values; ${ }^{* *}$ Information is based on main models and pooled data when available (if not, data of separate models/classes was used). Some studies included more than one attribute related to a particular domain. Totals could hence exceed the total number of studies incorporated. 


\section{Overall preferences and comparison of vaccinees and representatives}

A total of 96 attributes were identified in high-quality studies. Attributes were most commonly classified as outcome (43.8\%), followed by process (24.0\%), other (18.8\%) and cost (13.5\%). Attributes covered sixteen domains. Figure 2 showed that the same domains were valued by vaccinees and representatives. The outcome measure vaccine effectiveness was most often preferred regardless target group. The order of the remaining domains showed slight differences (Additional file 6). Vaccine risk as well as duration of protection (both outcome-related), were for instance more important for vaccinees compared to representatives, while representatives valued costs of vaccines and dosing \& visits more than vaccinees (cost and process-related). For both target groups, vaccine accessibility (process) was least preferred. Statistical significance was reported (or could be determined) in sixteen studies and was most often defined by using $p<0.01$. The average sample size was 1080. Studies with sample sizes above 500 usually applied multiple thresholds to determine at which point attributes were (not) statistically significant (e.g. $\mathrm{p}<0.01$, $p<0.05$ and $p<0.10)$. Although studies capturing preferences of vaccinees reported statistical significance more often, overall results showed that for both target groups outcome and cost-related domains were most frequently significant. The domain other disease related factors (other) was not statistically significant and vaccine accessibility (process) was an equal amount of times significant (at $\mathrm{p}<0.05)$ and insignificant (Additional file 7).

\section{Comparison of high- and lower-quality studies}

Eight lower-quality studies focused on vaccinees, fifteen on representatives and three on health advisors (Additional file 5). In line with the approaches used for highquality studies, studies targeting health advisors [37, 61, 70] were added to the representatives' category and outcomes of Verelst, Kessels, Delva, Beutels \& Willem [73] were split (and grouped under vaccinees as well as representatives). As a result, eighteen studies targeted vaccinees and 27 representatives.

A total of 243 attributes were used, most of which were outcome-related (39.1\%). Compared to high-quality studies, two domains were introduced by lower-quality studies: vaccine content and other (both other). The former referred to substances/components of vaccines such as preservatives and the latter included attributes that could not be grouped under the other seventeen domains (e.g. vaccine testing). All domains that were most often reported and most commonly statistically significant corresponded with high-quality studies, except for disease risk (other). An increased preference for disease risk was observed across both target groups. Another inconsistency refers to the sample sizes. Average sample sizes of lower-quality studies were 518 compared to 1080 in high-quality studies. Lower-quality studies tended to use stricter $p$-value thresholds for sample sizes below 500, while $p<0.05$ was often used for sample sizes above 500. In accordance with high-quality studies, domains related to process and other were least found statistically significant for both target groups. A more detailed comparison of high- and lower-quality studies in enclosed in Additional file 8.

\section{Discussion}

The growing body of SP literature on vaccination highlights the increased interest in the use of choice-based experiments, to elicit preferences for a variety of vaccines and to understand factors influencing vaccine decision-making of different groups of individuals. A total of 42 studies were identified in this review, capturing preferences of three different target groups and covering fourteen vaccines or vaccine programs. Given the limited amount of studies assessing preferences of health advisors, this review focused on examining and comparing preferences for vaccine attributes of vaccinees and representatives (including health advisors). The former generally focused on preferences of adults and adolescents, while the latter mainly captured parental preferences for childhood vaccines.

Among the 42 included studies, sixteen studies were of high-quality and could be included in the comparison of vaccine preferences. Irrespective of target group captured, outcome-related attributes, such as vaccine effectiveness, vaccine risk and protection duration, were most frequently reported, followed by attributes covering the monetary cost of vaccines. Outcome- and cost-related attributes were also most commonly statistically significant across all studies, indicating that the same factors are generally preferred across different groups of individuals. Correspondence was also observed for least preferred attributes, since attributes related to a vaccines' access were least valued by both target groups. However, it should be noted that elements of accessibility might already be included in other attributes such as in cost (see Verelst et al. [73]). Therefore, it should be interpreted cautiously.

The overall finding is in line with the review of Lack et al. [21], which focused on HPV-vaccination and found that vaccinees, parents and providers have the strongest preferences for attributes related to vaccine outcomes. Comparable patterns were also identified among earlier reviews of CAs [20] and DCEs [19]. Michaels-Igbokwe et al. [19] indicated for instance that attributes related to degree/duration of protection and risk were most often statistically significant across DCEs studying preferences 
for childhood and adolescent vaccines. In addition, attributes included in DCEs generally addressed features of vaccines, while neglecting service (i.e. process) or contextual aspects (i.e. other). The latter was observed to a lesser extend in this review, as nearly half of the highquality studies incorporated attributes describing coverage rates, waiting times, access, locations, information provision or social support. A more plausible explanation would be that aspects of a vaccine process are simply less important for vaccinees and representatives in making vaccine decisions. This hypothesis is supported by findings of Guo et al. [55], outlining that service convenience and quality are less 'dramatic' than vaccine features.

Current findings showed that outcome-related attributes were more often statistically significant in studies targeting vaccinees (esp. vaccine risk), while cost-related attributes were more often statistically significant in studies of representatives. This indicates that the level of evidence for outcomes and costs slightly differed between both target groups. However, outcome and cost parameters were statistically significant in both target groups, indicating no differences in preferences of vaccinees and representatives. Instead, differences for cost might be (partly) explained by the definition of this domain. Particularly among studies targeting representatives, cost-related attributes were operationalized differently (e.g. 'type and value of parental reward' and 'payment for one doctor visit'). This might have affected the way in which respondents interpreted attributes and eventually how they valued vaccine scenarios.

The robustness analysis confirmed findings of the main analysis and only showed a slight increase in preference for attributes covering disease risk (in both target groups). This suggests, in line with qualitative research on vaccine behaviour and the Health Belief Model [7981], that epidemiological and affective factors, such as the susceptibility to and severity of diseases, may also affect vaccine decisions. The discrepancy could also be caused by the conceptual overlap identified in the quality assessment. Four lower-quality studies included more than one risk-related attribute, while no high-quality study did. According to Mandeville et al. [30] overlap could distort parameter estimates, as attributes (and effects) are not distinct and do not vary independently. Respondents might for instance experience difficulties in distinguishing and interpreting attributes.

When examining characteristics of the studies, it is observed that all high-quality studies were conducted in HICs and applied MXL/RPL or LCM. They mainly focused on vaccines against sexually transmitted infections, while lower-quality studies were characterized by a broader range of vaccines, countries and econometric models. High-quality studies were also more likely to express outcomes in WTP or predicted vaccine uptake. The latter is in contrast to Clark et al. [17] who focused on general health preferences and observed a decline in the use of monetary values and probabilities. However, probabilities are particularly useful in vaccination, as herd immunity is an important externality which can only be acquired when vaccination coverage passes a certain threshold [14, 82, 83]. Adult and traveller vaccines might also require (co-)payments, which can be adequately captured in monetary values [77]. The trend of using more sophisticated designs and appropriate software, observed in the review of Soekhai [18], is reinforced by current findings. A last observation was that high-quality studies used larger sample sizes compared to lower-quality studies. Moreover, the high-quality studies with larger sample sizes $(\geq 500)$ were inclined to use multiple thresholds (i.e. alphas), whereas lowerquality studies used smaller alphas for sample sizes below 500 and $p<0.05$ for sample sizes above 500 . Which is contradicting with previous research that indicates that larger sample sizes are required when lowering alpha and vice versa $[84,85]$.

In the quality assessment, the average score was almost one point higher than reported by MichaelsIgbokwe et al. in 2017 (8.4 vs. 9.3) [19]. This suggests that choice-based experiments improved elements of design. However, no improvement was observed in our quality scores per period. The quality assessment also indicated that industry-funded studies scored remarkably lower than non-industry funded studies. This addresses the need to get insight into industry sponsorship and used methodology. In line with previous reviews who used the 13-criteria checklist $[19,30]$, no study reached the maximum score: all failed at least one criterion. Weaknesses were particularly observed on elements of choice task design, experimental design and conduct. This underlines once again the technical requirements for all four stages and highlights the need to improve scientific rigour across choice-experiments in health.

\section{Strengths and weaknesses}

A strength of this study is the use of a formal quality assessment tool [30] to critically appraise the methodological quality and internal validity of included studies. Due to this tool and the quality threshold, conclusions regarding the drivers of vaccine decisions were based on attributes of high-quality studies only [30, 32, 86]. The robustness was also tested and confirmed. Based on this, it could be ascertained that findings were largely not affected by exclusion of lower-quality studies [87]. The comprehensiveness of the search is also a strength. The primary search was updated and related reviews were screened. Only two additional studies were identified, confirming the accuracy of key words used and 
suggesting that the primary was all-encompassing [26]. However, data was extracted from published literature and relied on what was reported in articles and available supplementary material. Like in any review, reporting and publication bias could hence not be eliminated [86, 88]. In contrast to previous research, no in- or exclusion criteria were formulated based on vaccine topic or site examined. Included studies covered a variety of vaccines/programs, populations and settings, which promoted the generalisability of results [87]. Due to the limited research on preferences in low-resource countries and of healthcare professionals, both were still underrepresented which may hamper the generalisability to these particular populations and settings.

Beside strengths, some limitations could also be identified. Key steps of this review were for instance performed by a single researcher, which may have induced reporting bias [32, 86, 88]. To minimize the occurrence of inconsistencies/mistakes, all steps were closely monitored and checked by a second researcher and ambiguities were discussed and agreed upon. To reduce the number of attributes, the commonly used classification of outcome, cost and process was used [21, 89-91]. However, multiple attributes could not be classified properly, and a fourth category needed to be added. The variety of attributes included hampered appropriate naming and interpretation of this category as a whole. Besides, we decided to include health advisors into the representatives' group, because both referred to individuals that make vaccine decisions for others. Only four studies focused on health advisors, due to which it was considered inappropriate to create a separate group. Analyses revealed that no new domains were introduced by the studies of health advisors, indicating that this decision had no influence on the findings about representatives. Last of all, drivers were based on frequency of reporting and statistical significance of domains instead of relative importance scores per attribute. Given the range of vaccines, attributes, choice tasks, populations and outcome measures within included studies, a metaanalysis was not possible [92]. Although both measures give an indication about the importance of attributes, the adequacy is discussible. Statistical significance is not only contingent upon the set of attributes used, but also on the way in which it is defined $[32,84,85]$. Different choices in p levels (for instance $p<0.10$ vs $p<0.01$ ) can influence the frequencies reported per domain. Moreover, the frequency of reporting domains was also skewed by studies including more than one attribute of the same domain. Both hampered interpretability and may have induced bias on outcome level. Nonetheless, this was tried to minimize by accounting for significance levels (alphas) used and the amount of studies reporting certain domains.

\section{Implications for research and policy Implications for research}

The quality assessment showed that the choice task, experimental design and elements of conduct received less attention compared to analysis. Studies conducted in LMICs particularly reported inappropriate experimental designs, showed conceptual overlap and failed to pilot test the survey. Although Michaels-Igbokwe et al. [19] observed similar methodological patterns in 2017, choice experiments in vaccination have not yet structurally improved their designs and conduct. The time lag between the conduct and publication of results could play a role, as high-quality studies were on average published three years after its conduct. Improvements in choice design and conduct are notwithstanding crucial to ensure reliable estimates of vaccine preferences. As recommended by Soekhai et al. [18] this might be facilitated by formulation of guidelines to report choice experiments. Furthermore, future research could broaden the approaches used to measure SP (e.g. add contingent valuation) to adequately capture preferences of health professionals. Literature $[9,93,94]$ showed that decision strategies particularly differ for medical professionals and vaccinees. In this review only a limited amount of studies on preferences of health professionals could be included. Additional research could also focus on target groups other than those distinguished in this review (e.g. policy makers, based on gender) or on vaccine preferences in low-resource settings. A combination would also be interesting as qualitative research $[95,96]$ indicated that national decision-makers in LMICs particularly preferred simplified delivery mechanisms, thermostability and an extended shelf-life. In light of the current corona pandemic, it would also be worthwhile to assess preferences for (future) vaccines against epidemic infections, such as COVID-19 and SARS.

\section{Implications for policy}

In contrast to previous qualitative studies [9, 11, 12], this review demonstrates that vaccine preferences show similar patterns for vaccinees and representatives. Broadly the same strategies could be adopted to promote and optimize vaccination behaviour. Strategies should focus on outcomes, for instance by providing proper and understandable information about the effectiveness of vaccines, duration of effectiveness and risks associated with vaccine administration, dosing and handling. Insight into the latter is particularly important for vaccinees. Effective pricing strategies should be applied (if applicable) when introducing or continuing the use of vaccines. Particularly for vaccine decisions that involve representatives (e.g. childhood vaccines), the element of cost is important. The robustness analysis indicates that disease risk is important for vaccinees and 
representatives as well. Therefore, information strategies should not only cover vaccine-related aspects, but should also inform target groups about the severity and probability of diseases. Across included studies, individuals value a reduced number of doses/visits when deciding for themselves and others. Vaccine programs that currently include multiple injections (such as HPV and COVID-19 vaccines), should hence try to minimize the amount of dosages as much as possible.

\section{Conclusion}

Where previous literature reviews were restricted to specific target groups, type of vaccines or formats of choice experiments, this review was the first to examine vaccine preferences of different target groups across vaccines. A clear and comprehensive overview of current SP literature was provided, which did not only give insight into the four main drivers of vaccine decision-making and the correspondence between vaccinees and representatives, but also indicated room for improvement across three of the four stages of choice experiments. Future research into vaccine preferences of target groups other than vaccines and representatives and among groups in low-resource settings would give insight into the generalizability of current findings.

\section{Abbreviations}

ADCE: Adaptive discrete choice experiment; CA: Conjoint analysis; CLM: Conditional logit model; DCE: Discrete choice experiment; HIC: Highincome-country; ISPOR: International society for pharmacoeconomics and outcomes research; LCM: Latent class model; LMIC: Low-middle-incomecountry; MNL: Multinomial logit model; MXL: Mixed logit model; RP: Revealed preferences; RPL: Random parameter logit model; SP: Stated preferences; UMIC: Upper-middle-income country; WTP: Willingness-to-pay

\section{Supplementary Information}

The online version contains supplementary material available at https://doi. org/10.1186/s12879-021-06398-9.

Additional file 1: Overview of search strategy. A table describing the search applied in each of the databases.

Additional file 2: Overview of study characteristics. A complete overview of the characteristics of all studies included in this review.

Additional file 3: Overview of attributes included in each category/ domain. A table giving insight into the way attributes were grouped under categories and domains.

Additional file 4: Quality assessment. A detailed description of the outcomes of the quality assessment performed.

Additional file 5: Overview of vaccine attributes per study. A detailed overview of the vaccine attributes and domains used in each of the studies (incl. Statistical significance).

Additional file 6: Importance rankings vaccine attributes. Tables outlining the frequency in which domains were reported among highand lower-quality studies.

Additional file 7: Relative statistical significance (overall preferences). Tables giving insight into the amount of times domains were reported statistically significant in all studies (overall preferences).

Additional file 8: Comparison of high- and lower-quality studies. A more detailed description of findings of the robustness analysis.

\section{Acknowledgements}

We would like to thank the reviewers for their time, effort and feedback on our manuscript.

\section{Authors' contributions}

IvdP, MD and $\mathrm{MH}$ conceived this study and were involved in the conception and design of the study. MD conducted the data collection, analysis and interpretation and drafted the manuscript. IvdP supported the collection and interpretation of the data and performed a check for quality control. $\mathrm{MH}$ critically reviewed the manuscript. All authors approved the final manuscript.

\section{Funding}

No funding was received for the conduct of this study.

\section{Availability of data and materials}

The datasets used and/or analyzed during the current study are available from the corresponding author on reasonable request.

\section{Declarations}

Ethics approval and consent to participate

Not applicable.

\section{Consent for publication}

Not applicable.

\section{Competing interests}

The authors declare that they have no competing interests.

\section{Author details}

${ }^{1}$ Faculty of Health Medicine and Life Sciences, Maastricht University, Universiteitssingel 40, 6229 Maastricht, Netherlands. ${ }^{2}$ Department of Health Services Research, Care and Public Health Research Institute (CAPHRI), Maastricht University, Duboisdomein 30, 6229 Maastricht, Netherlands.

Received: 7 December 2020 Accepted: 15 July 2021

Published online: 28 August 2021

\section{References}

1. European Centre for disease prevention and control. Individual decisionmaking and childhood vaccination, meeting report 24 May 2013. Stockholm: ECDC; 2013

2. Dubé E, Laberge $C$, Guay $M$, Bramadat $P$, Roy $R$, Bettinger J. Vaccine hesitancy, an overview. Human Vaccin Immunother. 2013;9(8):1763-73. https://doi.org/10.4161/hv.24657.

3. Hensher D, Rose J, Greene W. Applied choice analysis. 2nd ed. Cambridge: Cambridge University Press; 2015. https://doi.org/10.1017/CBO978131613 6232.

4. Brown KF, Kroll JS, Hudson MJ, Ramsay M, Green J, Long SJ, et al. Factors underlying parental decisions about combination childhood vaccinations including MMR: a systematic review. Vaccine. 2010;28(26):4235-48. https:// doi.org/10.1016/j.vaccine.2010.04.052.

5. Harmsen IA, Ruiter RAC, Paulussen TGW, Mollema L, Kok G, de Melker HE. Factors that influence vaccination decision-making by parents who visit an anthroposophical child welfare center: a focus group study. Adv Prev Med. 2012;2012:1-7. https://doi.org/10.1155/2012/175694.

6. Chung Y, Schamel J, Fisher A, Frew PM. Influences on immunization decision-making among US parents of young children. Matern Child Health J. 2017:21(12):2178-87. https://doi.org/10.1007/s10995-017-2336-6.

7. Wachob DA, Boldy A. Social media's influence on parents' decisionmaking process of child vaccinations. Epidemiol Biostat Public Health. 2019;16(1):1-5.

8. Sisson $\mathrm{H}$, Wilkinson $\mathrm{Y}$. An integrative review of the influences on decisionmaking of young people about human papillomavirus vaccine. J Sch Nurs. 2019;35(1):39-50. https://doi.org/10.1177/1059840518805816.

9. Zikmund-Fisher BJ, Sarr B, Fagerlin A, Ubel PA. A matter of perspective: choosing for others differs from choosing for yourself in making treatment decisions. J Gener Int Med. 2006;21(6):618-22. https://doi.org/10.1111/j.152 5-1497.2006.00410.x

10. Ministry of Health. Immunisation handbook 2017. 2nd ed. Wellington: Ministry of Health; 2018. 
11. Goldstein WM, Weber EU. Content and discontent: indications and implications of domain specificity in preferential decision making. Psychol Learn Motiv. 1995;32:83-136. https://doi.org/10.1016/S0079-7421 (08)60308-4

12. Thompson $\mathrm{AGH}$. The meaning of patient involvement and participation in health care consultations: a taxonomy. Soc Sci Med. 2007;64(6):1297-310. https://doi.org/10.1016/j.socscimed.2006.11.002.

13. World Health Organization. Immunization coverage. 2019. https://www.who. int/en/news-room/fact-sheets/detail/immunization-coverage. Accessed 8 June 2019.

14. Strategic Advisory Group of Experts on immunization. 2018 assessment report of the global vaccine action plan. Geneva: WHO; 2018.

15. Louviere JJ, Hensher DA, Swait JD. Stated choice methods: analysis and applications. Cambridge: Cambridge University Press; 2000. https://doi.org/1 $0.1017 /$ CBO9780511753831.

16. Carlsson F. Non-market valuation: stated preference methods. In: Lusk JL, Roosen J, Shogren JF, editors. The Oxford handbook of the economics of food consumption and policy. Oxford: Oxford University Press; 2011. p. 181-215.

17. Clark MD, Determann D, Petrou S, Moro D, de Bekker-Grob EW. Discrete choice experiments in health economics: a review of the literature. Pharmacoeconomics. 2014;32(9):883-902. https://doi.org/10.1007/s40273014-0170-x.

18. Soekhai V, de Bekker-Grob EW, Ellis AR, Vass CM. Discrete choice experiments in health economics: past, present and future. Pharmacoeconomics. 2019;37(2):201-26. https://doi.org/10.1007/s40273-0180734-2.

19. Mickaels-lgbowke C, MacDonald S, Currie GR. Individual preferences for child and adolescent vaccine attributes: a systematic review of the stated preference literature. Patient. 2017;10(6):687-700. https://doi.org/10.1007/s4 0271-017-0244-x

20. Poulos C. A review of conjoint-analysis studies of vaccine preferences. In: ISPOR 21st annual international meeting; 2016 May 21-25. Washington DC: United States. Research Triangle Park: RTI Health Solutions; 2016.

21. Lack A, Hiligsmann M, Bloem $P$, Tünneßen M, Hutubessy R. Parent, provider and vaccinee preferences for HPV vaccination: a systematic review of discrete choice experiments. Vaccine. 2020;38(46):7226-38. https://doi.org/1 0.1016/j.vaccine.2020.08.078.

22. Dubé E, Gagnon D, MacDonald NE. SAGE working group on vaccine hesitancy. Strategies intended to address vaccine hesitancy: review of published reviews. Vaccine. 2015;33(34):4191-203. https://doi.org/10.1016/j. vaccine.2015.04.041

23. Sadaf A, Richards JL, Glanz J, Salmon DA, Omer SB. A systematic review of interventions for reducing parental vaccine refusal and vaccine hesitancy. Vaccine. 2013;31(40):4293-304. https://doi.org/10.1016/j.va ccine.2013.07.013.

24. Odone A, Fara GM, Giammaco G, Blangiardi F, Signorelli C. The future of immunization policies in Italy and the European Union: the declaration of Erice. Human Vaccin Immunother. 2015;11(5):1268-71. https://doi.org/10.1 080/21645515.2015.1019980.

25. Council of the European Union. Council Council recommendations on strengthened cooperation against vaccine-preventable diseases. OJEU. 2018; 446(1):1-17.

26. Wohlin C. Guidelines for snowballing in systematic literature studies and a replication in software engineering. In: EASE '14, Proceedings of the 18th International Conference on Evaluation and Assessment in Software Engineering; 2014 May 13-14. London. New York: Association for Computing Machinery; 2014.

27. De Bekker-Grob EW, Ryan M, Gerard K. Discrete choice experiments in health economics: a review of the literature. Health Econ. 2012;21(2):145-72. https://doi.org/10.1002/hec.1697.

28. Ryan M, Gerard K. Using discrete choice experiments to value health care programmes: current practice and future research reflections. Appl Heal Econ Heal Policy. 2003;2(1):55-64.

29. Moher D, Liberati A, Tetzlaff J, Altman DG. Preferred reporting items for systematic reviews and meta-analyses: the PRISMA statement. PLoS Med. 2008;6(7):e1000097.

30. Mandeville $\mathrm{KL}$, Lagarde $\mathrm{M}$, Hanson $\mathrm{K}$. The use of discrete choice experiments to inform health workforce policy: a systematic review. BMC Health Serv Res. 2014;14(1):367. https://doi.org/10.1186/14726963-14-367.
31. Munro BH. Statistical methods for health care research. 5th ed. Philadelphia: Wolters Kluwer Health/Lippincott Williams \& Wilkins; 2005.

32. Holly C, Salmond SW, Saimbert MK. Comprehensive systematic review for advanced nursing practice. New York: Springer Publishing Company; 2012

33. Centrale Commissie Mensgebonden Onderzoek. Uw onderzoek: WMOplichtig of niet?. N.d. https://www.ccmo.nl/onderzoekers/wet-enregelgeving-voor-medisch-wetenschappelijk-onderzoek/uw-onderzoekwmo-plichtig-of-niet. Accessed 20 Jan 2020.

34. Veldwijk J, Lambooij MS, Bruijning-Verhagen PCJ, Smit HA, de Wit GA. Parental preferences for rotavirus vaccination in young children: a discrete choice experiment. Vaccine. 2014;32(47):6277-83. https://doi.org/10.1016/j.va ccine.2014.09.004

35. Brown DS, Poulos C, Reed Johnson F, Chamiec-Case L, Messonnier ML. Adolescent girls' preferences for HPV vaccines: a discrete choice experiment. Adv Health Econ Health Serv Res. 2014;24:93-121. https://doi.org/10.1108/ S0731-219920140000024002.

36. Brown DS, Reed Johnson F, Poulos C, Messonnier ML. Mothers' preferences and willingness to pay for vaccinating daughters against human papillomavirus. Vaccine. 2010;28(7):1702-8. https://doi.org/10.1016/j.va ccine.2009.12.024

37. Lloyd AJ, Nafees B, Ziani E, Nicolas L, Fordham BA, Soubeyrand B, et al. What are the preferences of health care professionals in Germany regarding fully liquid, ready-to-use hexavalent pediatric vaccine versus hexavalent pediatric vaccine that needs reconstitution? Patient Prefer Adherence. 2015; 9:1517-24. https://doi.org/10.2147/PPA.S87229.

38. de Bekker-Grob EW, Jorien Veldwijk J, Jonker M, Donkers B, Huisman J, Buis $S$, et al. The impact of vaccination and patient characteristics on influenza vaccination uptake of elderly people: a discrete choice experiment. Vaccine. 2018;36(11):1467-76. https://doi.org/10.1016/j.vaccine.2018.01.054.

39. Adams J, Bateman B, Becker F, Cresswell T, Flynn D, McNaughton R, et al. Effectiveness and acceptability of parental financial incentives and quasimandatory schemes for increasing uptake of vaccinations in preschool children: systematic review, qualitative study and discrete choice experiment. Health Technol Assess. 2015;19(94):1-176. https://doi.org/10.331 0/hta19940

40. Poulos C, Yang JC, Levin C, Van Minh H, Giang KB, Nguyen D. Mothers' preferences and willingness to pay for HPV vaccines in Vinh Long Province. Vietnam Soc Sci Med. 2011;73(2):226-34. https://doi.org/10.1016/j. socscimed.2011.05.029.

41. Hall J, Kenny P, King M, Louviere J, Viney R, Yeoh A. Using stated preference discrete choice modelling to evaluate the introduction of varicella vaccination. Health Econ. 2002;11(5):457-65. https://doi.org/10.1002/hec.694.

42. Marshall HS, Chen G, Clark M, Ratcliffe J. Adolescent, parent and societal preferences and willingness to pay for meningococcal $B$ vaccine: a discrete choice experiment. Vaccine. 2016;34(5):671-7. https://doi.org/10.1016/j.va ccine.2015.11.075

43. Orme B. Sample size issues for conjoint analysis. In: Orme B, editor. Getting started with conjoint analysis: strategies for product design and pricing research. 4rd ed. Madison (WI): Research Publishers LLC; 2010. p. 57-65.

44. Hofman R, de Bekker-Grob EW, Richardus JH, de Koning HJ, van Ballegooijen M, Korfage IJ. Have preferences of girls changed almost 3 years after the much debated start of the HPV vaccination program in the Netherlands? A discrete choice experiment. PLoS One. 2014;9(8):e104772. https://doi.org/10.1371/journal.pone.0104772.

45. Ngorsuraches S, Nawanukool K, Petcharamanee K, Poopantrakool U. Parents' preferences and willingness-to-pay for human papilloma virus vaccines in Thailand. J Pharm Policy Pract. 2015;8(1):20. https://doi.org/10.1186/s40545015-0040-8.

46. Arbiol J, Yabe M, Nomura H, Borja M, Gloriani N, Yoshida S. Using discrete choice modeling to evaluate the preferences and willingness to pay for leptospirosis vaccine. Hum Vaccin Immunother. 2015;11(4):1046-56. https:// doi.org/10.1080/21645515.2015.1010901.

47. Bishai D, Brice R, Girod I, Saleh A, Ehreth J. Conjoint analysis of French and German parents' willingness to pay for meningococcal vaccine. Pharmacoeconomics. 2007;25(2):143-54. https://doi.org/10.2165/00019053-2 00725020-00006.

48. de Bekker-Grob EW, Hofman R, Donkers B, van Ballegooijen M, Helmerhorst TJM, Raat H, et al. Girls' preferences for HPV vaccination: a discrete choice experiment. Vaccine. 2010;28(41):6692-7. https://doi.org/10.1016/j.vaccine.2 010.08.001. 
49. Determann D, Korfage IJ, Fagerlin A, Steyerberg EW, Bliemer MC, Voeten HA, et al. Public preferences for vaccination programmes during pandemics caused by pathogens transmitted through respiratory droplets - a discrete choice experiment in four European countries, 2013. Euro Surveill. 2016; 21(22):pii=30247.

50. Determann D, Korfage IJ, Lambooij MS, Bliemer M, Richardus JH, Steyerberg EW, et al. Acceptance of vaccinations in pandemic outbreaks: a discrete choice experiment. PLoS One. 2014;9(7):e102505. https://doi.org/10.1371/ journal.pone.0102505.

51. Eilers $\mathrm{R}$, de Melker HE, Veldwijk J, Krabbe PFM. Vaccine preferences and acceptance of older adults. Vaccine. 2017;35(21):2823-30. https://doi.org/1 0.1016/j.vaccine.2017.04.014.

52. Flood EM, Ryan KJ, Rousculp MD, Beusterien KM, Block SL, Hall MC, et al. A survey of children's preferences for influenza vaccine attributes. Vaccine. 2011;29(26):4334-40. https://doi.org/10.1016/j.vaccine.2011.04.018.

53. Flood EM, Ryan KJ, Rousculp MD, Beusterien KM, Divino VM, Block SL, et al. Parent preferences for pediatric influenza vaccine attributes. Clin Pediatr. 2011;50(4):338-47. https://doi.org/10.1177/0009922810391247.

54. Gidengil C, Lieu TA, Payne K, Rusinak D, Messonnier M, Prosser LA. Parental and societal values for the risks and benefits of childhood combination vaccines. Vaccine. 2012;30(23):3445-52. https://doi.org/10.1016/j.vaccine.2012.03.022.

55. Guo N, Zhang G, Zhu D, Wang J, Shi L. The effects of convenience and quality on the demand for vaccination: results from a discrete choice experiment. Vaccine. 2017;35(21):2848-54. https://doi.org/10.1016/j.vaccine.2 017.04 .006$.

56. Hofman R, de Bekker-Grob EW, Raat H, Helmerhorst TJM, van Ballegooijen $M$, Korfage IJ. Parents' preferences for vaccinating daughters against human papillomavirus in the Netherlands: a discrete choice experiment. BMC Public Health. 2014;14(1):454. https://doi.org/10.1186/1471-2458-14-454.

57. Huang Z, Wagner AL, Lin M, Sun X, Zikmund-Fisher BJ, Boulton ML, et al. Preferences for vaccination program attributes among parents of young infants in Shanghai, China. Hum Vaccin Immunother. 2020;16(8):1905-101. https://doi.org/10.1080/21645515.2020.1712937.

58. Lambooij MS, Harmsen IA, Veldwijk J, de Melker H, Mollema L, van Weert YWM. Consistency between stated and revealed preferences: a discrete choice experiment and a behavioural experiment on vaccination behaviour compared. BMC Med Res Methodol. 2015;15(1):19. https://doi.org/10.1186/ s12874-015-0010-5.

59. Ledent E, Gabutti G, de Bekker-Grob EW, Alcázar Zambrano JL, Campins Martí M, Del Hierro Gurruchaga MT, et al. Attributes influencing parental decision-making to receive the Tdap vaccine to reduce the risk of pertussis transmission to their newborn - outcome of a cross-sectional conjoint experiment in Spain and Italy. Hum Vaccin Immunother. 2019;15(5):1080-91. https://doi.org/10.1080/21645515.2019.1571890.

60. Liao Q, Lam WWT, Wong CKH, Lam C, Chen J, Fielding R. The relative effects of determinants on Chinese adults' decision for influenza vaccination choice: what is the effect of priming? Vaccine. 2019;37(30):4124-32. https:// doi.org/10.1016/j.vaccine.2019.05.072.

61. Liao Q, Ng TWY, Cowling BJ. What influenza vaccination programmes are preferred by healthcare personnel? A discrete choice experiment. Vaccine. 2020;38(29):4557-62. https://doi.org/10.1016/j.vaccine.2020.05.012.

62. Oteng B, Marra F, Lynd LD, Ogilvie G, Patrick D, Marra CA. Evaluating societal preferences for human papillomavirus vaccine and cervical smear test screening programme. Sex Transm Infect. 2011;87(1):52-7. https://doi. org/10.1136/sti.2009.041392.

63. Pereira CCA, Mulligan M, Bridges JFP, Bishai D. Determinants of influenza vaccine purchasing decision in the US: a conjoint analysis. Vaccine. 2011; 29(7):1443-7. https://doi.org/10.1016/j.vaccine.2010.12.027.

64. Poulos C, Curran D, Anastassopoulou A, de Moerlooze L. German travelers' preferences for travel vaccines assessed by a discrete choice experiment. Vaccine. 2018;36(7):969-78. https://doi.org/10.1016/j.va ccine.2018.01.004

65. Poulos C, Reed Johnson F, Krishnarajah G, Anonychuk A, Misurski D. Pediatricians' preferences for infant meningococcal vaccination. Value Health. 2015;18(1):67-77. https://doi.org/10.1016/j.jval.2014.10.010.

66. Poulos C, Standaert B, Sloesen B, Stryjewska I, Janitsary A, Hauber B. Preferences for vaccines against children's diarrheal illness among mothers in Poland and Hungary. Vaccine. 2018;36(40):6022-9. https://doi.org/10.101 6/j.vaccine.2018.08.001.
67. Sadique MZ, Devlin N, Edmunds WJ, Parkin D. The effect of perceived risks on the demand for vaccination: results from a discrete choice experiment PLoS One. 2013;8(2):e54149. https://doi.org/10.1371/journal.pone.0054149.

68. Sapède C, Girod I. Willingness of adults in Europe to pay for a new vaccine: the application of discrete choice-based conjoint analysis. Int J Mark Res. 2002:44(4):463-76.

69. Seanehia J, Treibich C, Holmberg C, Müller-Nordhorn J, Casin V, Raude J. Quantifying population preferences around vaccination against severe but rare diseases: a conjoint analysis among French university students, 2016. Vaccine. 2017;35(20):2676-84. https://doi.org/10.1016/j.vaccine.2017.03.086.

70. Shono A, Kondo M. Mothers' preferences regarding new combination vaccines for their children in Japan, 2014. Hum Vaccin Immunother. 2017; 13(4):766-71. https://doi.org/10.1080/21645515.2016.1255387.

71. Shono A, Kondo M. Parents' preferences for seasonal influenza vaccine for their children in Japan. Vaccine. 2014;32(39):5071-6. https://doi.org/10.1016/ j.vaccine.2014.07.002.

72. Sun X, Wagner AL, Ji J, Huang Z, Zikmund-Fisher BJ, Boulton ML. A conjoint analysis of stated vaccine preferences in Shanghai. China Vaccine. 2020; 38(6):1520-5. https://doi.org/10.1016/j.vaccine.2019.11.062.

73. Verelst F, Kessels R, Delva W, Beutels P, Willem L. Drivers of vaccine decision-making in South Africa: a discrete choice experiment. Vaccine. 2019;37(15):2079-89. https://doi.org/10.1016/j.vaccine.2019.02.056.

74. Verelst F, Willem L, Kessels R, Beutels P. Individual decisions to vaccinate one's child or oneself: a discrete choice experiment rejecting free-riding motives. Soc Sci Med. 2018;207:106-16. https://doi.org/10.1016/j.socscimed.2 018.04.038.

75. Wang B, Chen G, Ratcliffe J, Afzali HHA, Giles L, Marshall H. Adolescent values for immunisation programs in Australia: a discrete choice experiment. PLoS One. 2017;12(7):e0181073. https://doi.org/10.1371/journal. pone.0181073.

76. Wong CKH, Man KKC, Ip P, Kwan M, McGhee SM. Mothers' preferences and willingness to pay for human papillomavirus vaccination for their daughters: a discrete choice experiment in Hong Kong. Value Health. 2018;21(5):622-9. https://doi.org/10.1016/j.jval.2017.10.012

77. Lancsar E, Louviere J. Conducting discrete choice experiments to inform healthcare decision making: a user's guide. Pharm Econ. 2008;26(8):661-77. https://doi.org/10.2165/00019053-200826080-00004.

78. Lancsar E, Louviere J, Flynn T. Several methods to investigate relative attribute impact in stated preference experiments. Soc Sci Med. 2007;64(8): 1738-53. https://doi.org/10.1016/j.socscimed.2006.12.007.

79. Schmid P, Rauber D, Betsch C, Lidolt G, Denker ML. Barriers of influenza vaccination intention and behaviour - a systematic review of influenza vaccine hesitancy, 2005-2016. PLoS One. 2017;12(1):e0170550. https://doi. org/10.1371/journal.pone.0170550.

80. Chapman GB, Coups EJ. Emotions and preventive health behaviour: worry, regret and influenza vaccination. Health Psychol. 2006;25(1):82-90. https:// doi.org/10.1037/0278-6133.25.1.82.

81. Bond L, Noland T. Making sense of perceptions of risk of diseases and vaccinations: a qualitative study combining models of beliefs, decisionmaking and risk perception. BMC Public Health. 2011;11(1):943. https://doi. org/10.1186/1471-2458-11-943.

82. Fine $P$, Eames K, Heymann DL. "Herd immunity": a rough guide. Clin Infect Dis. 2011;52(7):911-6. https://doi.org/10.1093/cid/cir007.

83. European Council. The state of health of vaccination in the EU. Rome: EC; 2014.

84. de Bekker-Grob EW, Donkers B, Jonker MF, Stolk EA. Sample size requirements for discrete-choice experiments in healthcare: a practical guide. Patient. 2015;8(5):373-84. https://doi.org/10.1007/s40271-015-0118-z.

85. Lakens D, Adolfi FG, Albers CJ, Anvari F, Apps MAJ, Argamon SE, et al. Justify your alpha. Nat Hum Beh. 2018;2(3):168-71. https://doi.org/10.1038/s41562018-0311-X.

86. Boutron I, Page MJ, Higgins JPT, Altman DG, Lundh A, Hróbjartsson A. Chapter 7: considering bias and conflicts of interest among the included studies. In: Higgins JPT, Thomas J, Chandler J, Cumpston M, Li T, Page MJ, Welch VA, editors. Cochrane handbook for systematic reviews of interventions version 6.0 (updated July 2019). 2019. https://training.cochra ne.org/handbook/archive/v6. Accessed 8 Aug 2020.

87. Polit DF, Beck $C T$. Nursing research. Generating and assessing evidence for nursing practice. 10th ed. Philadelphia: Wolters Kluwer Health/Lippincott Williams \& Wilkins; 2017. 
88. Drucker AM, Fleming P, Chan A. Research techniques made simple: assessing risk of bias in systematic reviews. J Invest Dermatol. 2016;136(11) 109-14.

89. Bien DR, Danner M, Vennedey V, Civello D, Evers SM, Hiligsmann M. Patients' preferences for outcome, process and cost attributes in cancer treatment: a systematic review of discrete choice experiments. Patient. 2017: 10(5):553-65. https://doi.org/10.1007/s40271-017-0235-y.

90. Sain N, Willems D, Charokopou M, Hiligsmann M. The importance of understanding patient and physician preferences for psoriasis treatment characteristics: a systematic review of discrete- choice experiments. Curr Med Res Opin. 2020;36(8):1257-75. https://doi.org/10.1080/03007995.2020.1 776233

91. Schaarschmidt M-L, Schmieder A, Umar N, Terris D, Goebeler M, Goerdt S, et al. Patient preferences for psoriasis treatments: process characteristics can outweigh outcome attributes. Arch Dermatol. 2011;147(11):1285-94. https:// doi.org/10.1001/archdermatol.2011.309.

92. Littell J, Corcoran J, Pillai V. Systematic reviews and meta-analysis. New York: Oxford University Press; 2008. https://doi.org/10.1093/acprof:oso/978019532 6543.001.0001.

93. Wroe AL, Turner N, Salkovskis PM. Understanding and predicting parental decisions about early childhood immunizations. Health Psychol. 2004;23(1): 33-41. https://doi.org/10.1037/0278-6133.23.1.33.

94. Wroe AL, Bhan A, Salkovskis P, Bedford H. Feeling bad about immunising our children. Vaccine. 2005;23(12):1428-33. https://doi.org/10.1016/j.va ccine.2004.10.004.

95. Kristensen DD, Bartholomew K, Villadiego S, Lorenson K. What vaccine product attributes do immunization program stakeholders value? Results from interviews in six low- and middle-income countries. Vaccine. 2016; 34(50):6236-42. https://doi.org/10.1016/j.vaccine.2016.10.057.

96. Neuzil KM. Data and product needs for influenza immunization programs in low- and middle-income countries: rationale and main conclusions of the WHO preferred product characteristics for next-generation influenza vaccines. Vaccine. 2017;35(43):5734-7. https://doi.org/10.1016/j.vaccine.2017. 08.088 .

\section{Publisher's Note}

Springer Nature remains neutral with regard to jurisdictional claims in published maps and institutional affiliations.

Ready to submit your research? Choose BMC and benefit from:

- fast, convenient online submission

- thorough peer review by experienced researchers in your field

- rapid publication on acceptance

- support for research data, including large and complex data types

- gold Open Access which fosters wider collaboration and increased citations

- maximum visibility for your research: over $100 \mathrm{M}$ website views per year

At BMC, research is always in progress.

Learn more biomedcentral.com/submissions 